\title{
El italiano contemporáneo por hispanohablantes: aspectos fonológicos ${ }^{1}$
}

Silvio Maggi

Universitat de Girona

\begin{abstract}
Este artículo quiere hacer resaltar las potenciales dificultades para estudiantes hispanohablantes en el aprendizaje del nivel fonológico del italiano: por lo tanto, se analizan las últimas tendencias del italiano contemporáneo con referencia al nivel segmental y al nivel prosódico con el objetivo de mejorar la competencia fonológica del estudiante en contextos comunicativos. Se presentan también, en algunos casos, ejercicios prácticos por utilizarse en clase cuando necesario.
\end{abstract}

Palabras clave: italiano como idioma extranjero, idioma español, fonología segmental y prosódica, transfert lingüístico positivo y negativo.

\begin{abstract}
This paper highlights the potential difficultues for Spanish mother tongue students learning Italian from the point of view of phonology: it analyses the latest trends in contemporary spoken Italian at a segmental and prosodic level with the aim of facilitating the acquisition of phonological fluency and accuracy in meaningful contexts for the foreign language students. It also provides, in some cases, practical exercises to be adopted in classroom contexts when necessary.
\end{abstract}

Key words: teaching Italian as a foreign language, Spanish language, segmental and prosodic phonology, positive and negative language transfer.

1. Este artículo es una revisión muy ampliada, sobre todo en relación con las últimas tendencias del italiano contemporáneo, de un estudio nuestro que apareció en 2001 en la revista Educación de la Facultad de Ciencias de la Educación de la Universidad Nacional San Cristóbal de Huamanga, Ayacucho, Perú, Año 5, núm. 9 (julio de 2001), p. 6-18, con el título: «El aprendizaje del italiano por hispanohablantes: nivel fonológico». Concebido inicialmente como manual didáctico para estudiantes de Perú y Bolivia, este artículo, profundamente revisado, puede ser útil para todos los estudiantes de habla española que empiezan el aprendizaje del italiano. 


\section{Introducción}

El aprendizaje de los idiomas extranjeros, aun cuando pertenecen a la misma familia lingüística neolatina, como el italiano y el español, requiere siempre de una gran atención y precisión por los detalles y por eso es muy importante conocer y resaltar las diferencias (y semejanzas) que existen entre los dos idiomas en los diferentes niveles lingüísticos.

En este trabajo queremos analizar las principales diferencias entre el italiano y el español en el nivel fonológico y ver cómo y cuánto esas diferencias pueden dificultar el aprendizaje del italiano contemporáneo por hispanohablantes. Hablamos de italiano contemporáneo porque hay tendencias innovadoras en el sistema lingüístico italiano en todos los niveles de análisis y creemos que es necesario tenerlas en cuenta en la enseñanza del idioma para extranjeros. Por eso, aunque manteniéndonos al máximo en el marco del italiano estándar (concepto que aquí simplificaremos mucho y connotaremos como el uso lingüístico que toda la comunidad de hablantes reconoce correcto), ${ }^{2}$ en algunas situaciones proveemos informaciones sobre detalles de tendencia fonológica que es mejor conocer.

La metodología que seguiremos en el presente trabajo es una comparación ágil pero exhaustiva entre el italiano y el español en el nivel fonológico: tendremos en cuenta también el excelente trabajo contrastivo en el nivel fonológico de Mazzotta, ${ }^{3}$ aunque aquí nuestros objetivos son más de naturaleza puramente didáctica; consideramos como italiano estándar contemporáneo el florentino actual, sin sus rasgos más marcados de variación sociolingüística y estilística, pero pondremos atención a las últimas tendencias, sobre todo del idioma hablado. El objetivo es didáctico; así pues, trabajaremos con el sistema de la lengua (fonemas y, cuando sea importante, alófonos), dejando aquí la teoría puramente fonética, que es utilísima para otras impostaciones investigadoras. En los casos en que sea necesario (cuando transcribimos la pronunciación real de la palabra con sus alófonos) representaremos fonéticamente sonidos y palabras entre corchetes [ ]; para el resto utilizaremos las barras de la transcripción fonológica / /. Utilizaremos antilambdas < > para grafemas y ortografía y representaremos el acento de palabra con ('), según los criterios del IPA. Además, queriendo proveer a los estudiantes de instrumentos prácticos y que puedan utilizarse rápidamente, daremos de vez en cuando unas sugerencias prácticas para la correcta pronunciación de algunos fonemas y secuencias de fonemas que caracterizan al italiano. Naturalmente, esta investigación quiere ser de ayuda para la didáctica y es importante especificar que consideramos prioritaria la competencia comunicativa en la enseñanza de lenguas extranjeras; por

2. Para una panoràmica completa sobre el italiano contemporáneo véase D’ACHILLE, Paolo. L'italiano contemporaneo. Bolonia: Il Mulino, 2003. La referencia a la definición del italiano estándar está en la p. 27.

3. La obra de MAZZOTTA, Giuseppe (Italiano, francese, spagnolo: sistemi fonologici a confronto. Bérgamo: Minerva Italica, 1984) trata con autoridad el problema de la comparación a nivel fonológico de los tres idiomas neolatinos y es la única referencia específica sobre este asunto. 
lo tanto, es mejor utilizar, como hicimos nosotros, estas sugerencias fonológicas en actividades comunicativas, como diálogos situacionales que se parezcan a la realidad cotidiana. También hemos tenido en cuenta, en algunos casos imprescindibles, la influencia de las variantes lingüísticas y sobre todo geográficas, que hoy en día son muy importantes en el complejo panorama del italiano contemporáneo, sobre todo hablado.

Empezaremos, pues, nuestro análisis con las vocales y consonantes (fonemas y alófonos), pasaremos luego a las secuencias de sonidos (sílabas y sintagmas) y finalmente nos ocuparemos del nivel prosódico del italiano (acento, ritmo, entonación).

\section{Diferencias en fonemas y secuencia de fonemas entre el italiano y el español}

a) Sistema vocálico

El sistema vocálico del italiano estándar se compone de siete vocales (y fonemas) en posición tónica y cinco en posición átona, y se representa por medio de un triángulo vocálico (véase la tabla 3 al final del artículo). El sistema vocálico del castellano estándar se compone de cinco vocales (y fonemas) en posición tónica y átona y también se puede representar con un triángulo vocálico, a diferencia de otros idiomas como el francés y el inglés, cuyos sistemas vocálicos suelen representarse por medio de un trapecio por la presencia de más vocales abiertas y más sonidos vocálicos en general. ${ }^{4}$

El italiano posee una vocal central, la /a/, tres vocales anteriores (o palatales), /ع/ (abierta), /e/ (cerrada), /i/, y tres vocales posteriores o (velares), / / / (abierta), /o/ (cerrada), /u/. También posee dos semivocales (y semiconsonantes), $/ \mathrm{j} / \mathrm{y} / \mathrm{w} /$, y en total nueve sonidos con función vocálica (sobre todo en los diptongos decrecientes, /j/ y /w/ actúan como semivocales). Este sistema vocálico puede generar algunos problemas a los estudiantes hispanohablantes a pesar de que el cuadro comparativo de las vocales de ambos idiomas es bastante parecido; ${ }^{5}$ en italiano, las semivocales (y semiconsonantes) $[\mathrm{j}],[\mathrm{w}]$ se consideran fonemas, aunque es complicado encontrar parejas mínimas con las vocales correspondientes /i/, /u/: /'spjanti/ ( $2^{\text {a }}$ persona del singular del verbo spiantare), /spi'anti/ (participio pasado plural del verbo spiare); /la'kwale/ la quale (pronombre relativo), /laku'ale/ lacua-

4. Véase los trabajos específicos de LAdefoged, Peter. A course in phonetics. Nueva York: Harcourt Bruce Jovanovich, 1982, y de CANEPARI, Luciano. Phonetic notation. Venecia: Cafoscarina, 1983.

5. Pensamos sobre todo en lo dicho por Quilis, Antonio; FernándeZ, Joseph A. Curso de fonética y fonología española para estudiantes angloamericanos. Madrid: CSIC, 1985. p. 52; por QUILIS, Antonio. Principios de fonología y fonética española. Madrid: Arco Libros, 1998. p. 40; MACHUCA, María. "Articulación y pronunciación del español». En: AlCOBA, Santiago (coord.). La expresión oral. Barcelona: Ariel, 2000. p. 45; CANEPARI, Luciano. Italiano standard e pronuncia regionale. Padua: Cleup, 1982. p. 149. 
le (del lago), ${ }^{6}$ que son parejas mínimas si no tenemos en cuenta las fronteras morfológicas y adoptamos un concepto fonológico muy concreto, próximo a los hechos fonéticos; ${ }^{7}$ todavía en italiano encontramos con más facilidad parejas mínimas de las semiconsonantes entre ellas y con otras consonantes: ['fjoko] y ['fwoko]; ['bjanko] y ['brayko]. ${ }^{8}$ En cambio, en castellano [j] y [w] son alófonos en función silábica de $/ \mathrm{i} / \mathrm{y} / \mathrm{u} /{ }^{9}$ y no fonemas en cuanto no determinan diferencias de significado entre parejas mínimas. Además, el italiano posee el diptongo «espontáneo» en sílaba

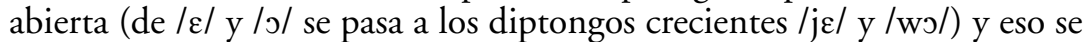
produce aun con diferencias fonéticas también en castellano), pero no en sílaba cerrada (/'fortsa/ vs. ['fwerӨa]; /'terra/ vs. ['tjerra]) y a veces los hispanófonos podrían producir diptongos innecesarios en la L2. Otros diptongos y los raros triptongos se realizan de manera bastante similar, salvo cuando los diptongos crecientes [we] y [wi] en el español se posponen a los fonemas velares sonoros y sordos $/ \mathrm{g} / \mathrm{y} / \mathrm{k} /$ (este último sólo cuando se realiza en grafías como <que, qui> pero no cuando es <cue, cui>, que es labiovelar: ['kwento], [kwi'sar]), como en guerra /'gerra/; quemar/ke'mar/; guitarra/gitarra/; quinto /'kinto/ y no se pronuncian. En cambio, en el italiano los diptongos crecientes [we] y [wi] siempre se pronuncian en las secuencias labiovelares (seguidos por otra vocal): / kw/ y /gw/, como en guerra /'gwerra/; quinto /'kwinto/. Se exceptúan las palabras castellanas con

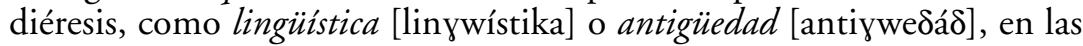
que el grupo [we] y [wi] se pronuncia igual que en italiano.

El italiano posee los fonemas vocálicos $/ \varepsilon / \mathrm{y} / \mathrm{J} /$, que son semiabiertos, como en /'peska/ (melocotón) y en /'botte/ (golpes), y que producen diferencias semánticas entre parejas mínimas /'peska/ (pesca) y l'botte/ (tonel); en español, los fonemas /e/ y /o/ presentan unos alófonos algo abiertos en algunas posiciones; por ejemplo, cuando entran en contacto con el sonido /rr/: es el caso de ['perro] perro y ['torre] torre; y en otros casos, antes del fonema /x/: ['texa] teja ${ }^{10}$ pero no producen diferencias semánticas entre parejas mínimas como en el italiano. Dado que sabemos que los alófonos son realizaciones concretas y diferentes (por razones geográficas, estilísticas, sociolingüísticas) de un mismo fonema y no afectan al sistema de la lengua, podríamos suponer ciertas dificultades para hispanohablantes en la diferenciación de parejas mínimas en italiano con oposición de las vocales medias anteriores y posteriores. Sin embargo, hay que considerar que

6. Véase D’ACHILle, op. cit, p. 80.

7. Véase Mioni, Alberto M. «Fonetica e fonologia». En: Sobrero, Alberto A. (coord.). Introduzione all'italiano contemporaneo: le strutture. Vol. 1. Roma-Bari: Laterza. p. 101-139. Aquí la referencia está en la p. 127.

8. Véase D'ACHILle, op. cit., p. 80.

9. Véase QuILIS, op. cit., p. 41.

10. En este sentido, las referencias son: NAVARro TOMÁs, Tomás. Manual de pronunciación española. Madrid: CSIC, 1961; QUILIS y FERNÁNDEZ, op. cit., p. 48-49; MACHUCA, op. cit., p. 44. 
en Italia, hoy en día, en el vocalismo tónico la oposición fonológica entre las vocales medio-altas (cerradas) y medio-bajas (abiertas) anteriores y posteriores es muy reducida y se produce sólo en la Italia central, en Florencia y en Roma, por ejemplo (con diferencias entre las dos pronunciaciones, como ['lettera], cerrado en Roma, y ['lettera], abierto en Florencia, o como [ko'lonna], abierto en Roma, y [ko'lonna], cerrado en Florencia. En otras partes de Italia prácticamente no hay oposición fonológica entre las vocales medias abiertas y cerradas, y el vocalismo tónico casi se reduce a cinco vocales, así como también el átono, y esa parece ser la tendencia del sistema actual, que podría ver las medio-altas y las medio-bajas reducidas a simples alófonos intercambiables o variantes regionales y estilísticas libres. ${ }^{11}$ Por lo tanto, creemos que esta situación no es muy problemática para estudiantes de habla española a pesar de que es necesario explicar toda la teoría fonológica sobre ese tema y la tendencia del italiano contemporáneo.

Un problema que puede aparecer con una vocal, causado por la transferencia lingüística del idioma materno, es la posible añadidura del fonema /e/ al inicio de las palabras italianas que empiezan por el fonema /s/ + consonante, como en el caso de /stu'dente/, /skwa'drone/, /'skwola/ y muchas otras, que pueden realizarse como [estu'dente], [eskwa'drone], [es'kwola]. ${ }^{12}$ Este caso de posible transferencia del idioma materno (que en diacronía, como el portugués, ha añadido una vocal prostética a las palabras que empiezan con ese nexo consonántico, diferenciándose así del italiano) ${ }^{13}$ se supera con la correcta pronunciación de las palabras italianas que empiezan con el fonema $/ s /$ + consonante. Es necesario hacer ejercicios de repetición oral en voz alta de estas palabras posiblemente en contextos comunicativos.

b) Sistema consonántico

El italiano posee veintiún fonemas consonánticos o bien treinta y seis si consideramos que quince de estos fonemas pueden ser tenues y dobles y generar diferencias semánticas entre parejas mínimas: /'fato/ hado y /'fatto/ hecho; l'pena/ pena y l'penna/ bolígrafo. Así pues, el número de fonemas italianos es de treinta, pero considerando la duración consonántica se podría llegar a cuarenta y cinco fonemas. Más en particular y basándonos en los trabajos de Canepari, ${ }^{14}$ Mioni, ${ }^{15}$ D’Achille, ${ }^{16}$ Quilis-Fernández ${ }^{17}$ y Machuca, ${ }^{18}$

11. Véase Mioni, op. cit., p. 136; D’ACHILle, op. cit., p. 92-93.

12. Véase también GAVAGNIN, Gabriella. «Per una grammatica degli errori di studenti catalani in italiano come L2». Quaderns d'Italià, núm. 3 (1998): 121-134, para una panorámica sobre problemas iguales encontrados por estudiantes de lengua materna catalana en el aprendizaje del italiano.

13. Véase Schmid, Stephan. Fonetica e fonologia dell'italiano. Turín: Paravia, 1999. p. 95.

14. Véase op. cit., p. 150.

15. Véase op. cit., p. 109.

16. Véase op. cit., p. 81.

17. Véase $o p$. cit., p. XXXI-XXXII.

18. Véase op. cit., p. 48. 
podemos observar que hay diferencias entre el sistema consonántico del español (que posee diecinueve fonemas consonánticos) y el del italiano (véase las tablas 1 y 2). Para el castellano, nos basamos en el esquema consonántico de Machuca y para el italiano seguimos a D’Achille, pero diferenciamos entre alveolopalatales y palatales de acuerdo con Canepari, porque la distinción (que existe sobre todo en la realidad fonética) es pertinente para los objetivos del estudio. Está claro que la realización práctica de / $\mathfrak{t} /$, que en italiano clasificamos como africado alveolopalatal sordo, y en castellano, como africado palatal sordo (de acuerdo con la literatura), es más o menos la misma: /tfok'kolata/ versus /tfo'kolate/; pero la distinción es más útil en el caso de las fricativas y africadas alveolopalatales sonoras.

Continuando, las consonantes que no existen en el español son: la fricativa labiodental sonora /v/; la fricativa palatal sorda / $/$ /; la africada alveolar sorda /ts/ y la africada alveolar sonora /dz/; la africada palatal sonora/d3/ (Quilis menciona el alófono africado palatal y sonoro [\$] de la fricativa sonora pala$\mathrm{tal} / \mathrm{j} / \mathrm{de}$ yugo ['juyo] y de cónyuge ['konjuxe], pero, como veremos en breve, este sonido se realiza de una manera bastante diferente, sobre todo por una fuerte intensidad, en el italiano: maggio /'madd3o/). ${ }^{19}$

Veamos en detalle cuáles son los sonidos consonánticos que no existen en el sistema del español, o que en cierto modo son diferentes en sus realizaciones, y que pueden representar dificultades para los hispanófonos. Proponemos a los lectores unas sugerencias para articular correctamente estos sonidos.

- /S/: fricativa alveolopalatal sorda como en /'Sena/ scena; /'Sentsa/ scienza. Para articular este sonido se puede partir de la pronunciación de /t fíko/ chico, y se puede alargar la consonante y redondear los labios para que el sonido sea fricativo. Es siempre doble en posición intervocálica l’asja/ ascia, con tendencia a ser tenue en las pronunciaciones del norte. Es importante notar que en el centro de Italia, incluyendo Florencia y Roma, se realiza con este sonido fricativo la africada palatal sorda $/ \mathrm{t} /$ (la del español chico) y se hará ['bafo] bacio, en lugar del estándar /'bat5o/.

- /v/: fricativa labiodental sonora. Al pronunciarla, los incisivos superiores tocan el labio inferior y se produce la vibración de las cuerdas vocales, como en /vi'gore/, /'verde/, /ve'rona/.

— /ts/: africada alveolar sorda. Se puede lograr pronunciando conjuntamente una /t/ y una /s/ sorda como en /'fortsal forza, /kan'tsone/ canzone, /'pottso/ pozzo.

- /dz/: africada alveolar sonora. Se puede lograr pronunciando conjuntamente una /d/ y una /s/ sonora como en /'mandzo/ manzo, /'gardza/ garza, /'dzingaro/ zingaro.

- /d3/: africada alveolopalatal sonora. No tiene equivalencia exacta en el español: según algunos es parecida a los sonidos de /'konjuxe/ y /'juyo/, entendién-

19. Véase QUILIS, op. cit., p. XXVIII y 108-9. 
dolos como /'kondзuye/ y /'dзuyo/; pero es una realización con rehilamiento típica de Latinoamérica ${ }^{20}$ y de todos modos se diferencia de la del italiano /'dsina/ (Gina) y /dse'lato/ (gelato), que es mucho más intensa. Se podría articular con la pronunciación conjunta de la $/ \mathrm{d} / \mathrm{y}$ de una $/ \mathrm{j} /$, que es un fonema del castellano con diversas variantes fonéticas, ya que puede realizarse con diferentes alófonos según su posición en la palabra ${ }^{21} \mathrm{o}$ bien, aún mejor, con la pronunciación conjunta de /d/ y de [3], que, en cuanto es alveolopalatal (en la realidad fonética), se diferencia de [i], que es dorsopalatal y es un fonema propio del francés (en <garage> por ejemplo), del catalán ['zirona] Girona, y alófono fricativo de la africada palatal sonora del italiano mencionada arriba en el habla florentina corriente: ['zallo] per /'sallo/.

- / $\lambda /$ : lateral palatal sonora. Existe en castellano pero se pronuncia como simple /' $\lambda$ ubia/ lluvia, /a $\lambda$ a'nar/ allanar, mientras que intervocálica es siempre doble en italiano y se escribe $<\mathrm{gl}>$, como en /ko'ni $\lambda \lambda_{\mathrm{o}} /$, coniglio, /'ma $\lambda \lambda \mathrm{a} /$, maglia. Atención, que $<\mathrm{gl}>$ en inicio de palabra en italiano no es palatal, sino velar /glit fe'rina/, /'globo/, /glu'cozio/, con la excepción del artículo y pronombre $/ * \lambda \mathrm{i} /$, gli, que es palatal y debe pronunciarse siempre como doble cuando está precedido por una palabra terminada en vocal (por reduplicación sintáctica). Señalamos aquí que en las hablas del norte este fonema se realiza como [li]: [ko'niljo], ['malja], mientras que en muchas zonas del centro-sur es [ji]: [ko'nijjo], ['majja] (pronunciación frecuente también en Roma y en aumento hoy en día. ${ }^{22}$

- /n/: nasal palatal sonora. Existe en las dos lenguas pero en el italiano se pronuncia siempre como doble cuando es intervocálica, como en /mon'tanna/, montagna. En cambio, en el español es siempre tenue: /mon'tana/. En inicio de palabra, en italiano, se pronuncia como doble en reduplicación sintáctica /*nokki/ gnocchi. Se escribe siempre <gn> y puede confundir a los hispanohablantes, porque en el español el grupo ortográfico <gn> es siempre velar: ['siyno], mientras que en el italiano es siempre palatal: /'senno/, segno.

Con el fin de practicar estos fonemas potencialmente complicados para hispanófonos, presentamos una serie de palabras italianas que incluyen los sonidos arriba expuestos:

Contraste $/ \mathrm{t} \int /-/ \mathrm{d}_{3} /$

$\begin{array}{ll}\text { Genova } & \text { civile } \\ \text { piacere } & \text { maggio } \\ \text { giulio } & \text { diciotto } \\ \text { marcio } & \text { buongiorno }\end{array}$


Contraste /ts/- /dz/

$\begin{array}{ll}\text { razzo } & \text { pazzo } \\ \text { zucchero } & \text { gazza } \\ \text { nazione } & \text { piazza } \\ \text { verza } & \text { ronza }\end{array}$

Aquí hay que considerar que la oposición fonológica entre /ts/ y /dz/ es muy limitada: /'rattsa/ estirpe y /'raddza/ raya (zool.). Además, como en el caso de las vocales medias abiertas y cerradas, hay diferencias en Italia en la distribución de los dos fonemas, así que en las hablas del norte [ts] nunca se pronuncia en inicio de palabra (en el estándar es posible: /'tsio / zio) y se hará [dz], mientras que en las hablas del sur se hará [dz] después de consonante: ['dandza] danza (en el estándar /'dantsa/). ${ }^{23}$ D'Achille, ${ }^{24}$ considerando la tendencia del sistema, también amplía al centro-sur la pronunciación sonora y tenue $[\mathrm{dz}]$ en inicio de palabra e intervocálica cuando la palabra no presenta la doble grafía: [a'dzsto] <azoto>, mientras que es siempre doble y sorda la $<\mathrm{z}>$ doble /'pittsa/ pizza (con la excepción de /ad'dzurro/ azul y otras que son dobles y sonoras). Recordemos que, como regla general, /ts/ y /dz/ son siempre dobles /tts/y $/ \mathrm{ddz} /$ en posición intervocálica y que, por tanto, en el estándar se hará /ad'dzoto/.25

Pronunciación de otros sonidos complicados:

$\begin{array}{lll}\text { Verona } & \text { avere } & \text { rivolta } \\ \text { pigna } & \text { segnale } & \text { sogno } \\ \text { paglia } & \text { famiglia } & \text { biglia } \\ \text { sciare } & \text { scendere } & \text { scientifico }\end{array}$

Naturalmente, será muy importante que los estudiantes de italiano repitan frecuentemente estos sonidos, resaltando las diferencias entre sordas y sonoras; además, aconsejamos el uso de cintas y vídeos para escuchar y ver cómo se articulan estos sonidos. Todas estas actividades de práctica fonológica irían incluidas en un marco comunicativo de la didáctica, o sea presentadas también por medio de diálogos situacionales, porque el objetivo principal es siempre la competencia pragmática del alumno en la realidad cotidiana.

Algunos sonidos que existen y se utilizan mucho en español no existen en italiano, como los alófonos de las oclusivas sonoras /b/, /d/ y /g/, que son fricativas en mitad de palabra: $[\beta],[\delta]$ y $/[\gamma]$. Eso puede originar una pronunciación incorrecta en el idioma extranjero: italiano /ka’bina/, español [ka’ßina]; italiano /la’drone/, español [la'oron]; italiano /'agosto/, español ['ayosto]. Como hemos visto más arriba, el castellano no posee la fricativa labiodental sonora $/ \mathrm{v} /$, que en grafía aparece como $<\mathrm{b}>$ y en fonología como la fricativa bilabial 


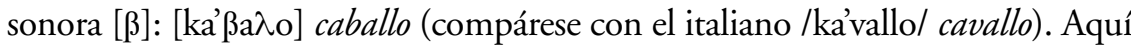
la transferencia lingüística negativa en el ámbito fonológico es muy probable: ${ }^{26}$ muchas palabras castellanas empiezan por $<\mathrm{v}>$ (que es un grafema pero no un fonema del español) pero con el fonema /b/: /'bino/ vino, /ba'lor/ valor, /'bela/ vela; pues se puede interpretar el italiano/ve'rona/ como [be'rona],

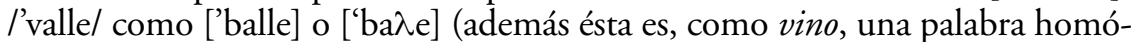
grafa y homónima en los dos idiomas pero no homófona), /volo/ como ['bolo], lo que causa problemas en la pronunciación y en la grafía (con frecuentes intercambios equivocados $\mathrm{de}\langle\mathrm{b}\rangle \mathrm{y}\langle\mathrm{v}\rangle$ en textos escritos).

Otro problema que puede originarse en el sistema consonántico es la presencia en castellano de la fricativa (inter)dental sorda $/ \theta /$, que no tiene equivalencia en el italiano, por lo que es posible que los hispanohablantes realicen el sonido interdental en casos no necesarios, engañados también por la frecuente semejanza homógrafa de palabras en las dos lenguas: italiano zona

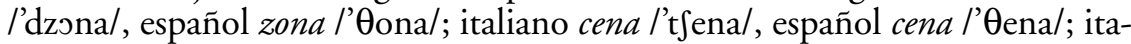
liano cielo l'trslo/, español cielo /'Ojelo/.

Luego se da el caso, como ya hemos visto al tratar las vocales, de los grupos españoles <gue-gui>, donde la semiconsonante no se pronuncia (es una velar pura), mientras que sí se debe pronunciar en italiano, donde el nexo es labiovelar: español guerra /'gerra/, italiano guerra l'gwerra/; español guiar /'giar/, italiano guidare /gwidare/. Lo mismo ocurre con la oclusiva velar sorda $/ \mathrm{k} /$ en los grupos <qui-que>, como en el italiano querela /kwerela/, español querella /keré $\lambda$ a/; italiano Quito /kwíto/, español Quito /kíto/.

Además, en el italiano la oclusiva velar sorda $/ \mathrm{k} /$ se puede realizar gráficamente (en contacto con vocales palatales) en los grupos <che-chi>, como en chimica /'kimika/; cherubino /keru'bino/; así que, por transferencia de las normas fonológicas del idioma materno ( $<\mathrm{ch}>$ corresponde a la africada palatal sorda $/ \mathfrak{t} / /)$, los hispanohablantes a menudo pronuncian las palabras de arriba como ['t $t$ imika] y [t $\mathrm{t}$ eru'bino], con lo que producen errores de pronunciación.

Lo mismo pasa con la oclusiva velar sonora /g/ en contacto con las vocales palatales, como en ghepardo /ge'pardo/y ghiro /'giro/. Un hispanófono podría encontrar dificultades para pronunciar correctamente estas secuencias

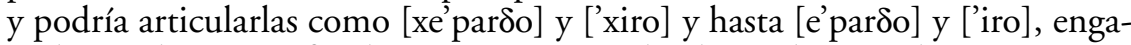
ñado por la ortografía (la pronunciación de ghepardo en italiano se acerca mucho a la del castellano guepardo /ge'paroo/.

Combinaciones de la consonante $/ s /$ con los grupos de sonidos arriba mencionados podrían crear más desventajas para los hispanohablantes. Veamos algunos ejemplos:

sghembo /'zgembo/

scherma l'skerma/

sguerciare /zgwer'tsare/

sgelare/zdse'lare/

26. Véase OdLIn, Terence. Language Transfer. Cambridge: CUP, 1989. Secciones 3.1 y 3.3. 
Además, en estas palabras, como hemos visto más arriba, se suele añadir frecuentemente una /e/ prostética inicial.

Las fricativas alveolares sorda /s/ y sonora /z/ (que es un fonema en italiano pero un alófono en español) están a veces en oposición en los dos idiomas: /'roza/ italiano y /'rrosa/ español, pero en italiano contemporáneo la oposición entre ambos fonemas es muy limitada ${ }^{27}$ y no tendría que representar un problema para su utilización.

Hemos considerado que existen consonantes en el sistema fonológico del italiano que el español no posee y otras que tienen diferentes realizaciones ortográficas de sonidos en los dos idiomas. Por lo tanto, profesores y estudiantes tendrán en cuenta estos fenómenos para enseñar y aprender. Aconsejamos a los profesores resaltar todas estas diferencias y a los estudiantes escuchar constantemente en el habla normal la pronunciación correcta de estos sonidos.

\section{La geminación y la reduplicación sintáctica en italiano}

La repetición consonántica es muy frecuente en el italiano y no sucede en el español (con la excepción de /rr/ y de algunas palabras con [nn]: [in'nokwo]). Por lo tanto, crea dificultades a los estudiantes de italiano; además, en italiano la geminación caracteriza semánticamente a parejas mínimas de palabras: /ka'pello/ capello, y /ka'ppello/ cappello; /'roza/ rosa, y /'rossa/ rossa; /'polo/ polo, y /'pollo/ pollo y muchas otras. El estudiante de italiano debe hacer el esfuerzo mental de concebir la doble consonante italiana como dos sílabas distintas (ros-sa, pol-lo), tal como es en la realidad fonética, en que la consonante larga se divide en dos partes por el límite silábico (el fenómeno se llama geminación; geminata en italiano), ${ }^{28}$ y tendrá que pronunciar dos veces la misma consonante.

A veces la persona de habla castellana puede transferir el hábito de pronunciar la $<\mathrm{r}>$ en inicial de palabras italianas como vibrante múltiple / $\mathrm{rr} /$ (fonema estándar del español: /'rroma/, /rre'mate/ y decir por lo tanto ['rrosso] y ['rrana] (redoblando la consonante cuando no es necesario), en lugar de /'rosso/ y /'ranal.

Además, en el italiano estándar existe el redoblamiento sintáctico (sobre todo en la Italia central), que consiste en reforzar la consonante de la segunda palabra en algunas secuencias de la misma cadena fónica (cuando la consonante no es doble por naturaleza y cuando no hay pausa entre las dos palabras): a Firenze [affi'rentse]; io e te [ioet'te]; a correre [ak'korrere]; pero: a sparare [as'parare] sin redoblamiento, porque /s/ + consonante ya es sílaba larga. Este redoblamiento ocurre después de monosílabos fuertes con acento (adverbios, pronombres, formas verbales) y débiles sin acento (preposiciones y conjunciones); después de palabras agudas (caffé, città, virtù, formas verbales del futuro

27. Véase D’Achille, op. cit., p. 93-94; Mioni, op. cit., p. 115-116.

28. Léase la definición de MALMERG, Bertil. Manuale di fonetica generale. Bolonia: Il Mulino, 1977. p. 228-229. 
y pasado remoto) y de algunos bisílabos (qualche, dove, come, sopra). En la Italia del norte se realiza sólo si el redoblamiento aparece en grafía (davvero, soprattutto, eccome), pero no si estas palabras se escriben separadas: e come, sopra tutto. Históricamente, el fenómeno se explica como un hecho de asimilación regresiva: muchas palabras que lo provocan acababan en consonante en latín y esa consonante se ha asimilado a aquella inicial de la palabra siguiente, redoblándola: supra ad totum > soprattutto; et bene > ebbene. Después, por analogía, el fenómeno se ha extendido a palabras que no acababan en consonante en latín, a todas las palabras italianas oxítonas y al léxico emotivo-expresivo. ${ }^{29}$ Teóricamente, el fenómeno se podría explicar con la cantidad vocálica (pero el debate está muy abierto): las vocales tónicas en italiano son siempre breves (también las vocales tónicas en sílaba cerrada) y quizás habría una tendencia a cerrar la sílaba final, redoblando la consonante inicial de la palabra siguiente. ${ }^{30}$

Esta particularidad idiomática es seguramente uno de los problemas más significativos que los hispanófonos encuentran en el nivel fonológico para hablar en italiano. Serán necesarias muchas repeticiones de consonantes dobles (y de reduplicación sintáctica en la cadena fónica) para permitir a los estudiantes de habla española acostumbrarse al redoblamiento (o bien a no redoblar cuando no hay que hacerlo, como en el caso de la / rr /). Sugerimos para la clase unas palabras para que los estudiantes escuchen y entiendan cuáles llevan consonantes dobles y luego las repitan correctamente.

Para el problema de las dobles consonantes en general: ${ }^{31}$

Ejercicio a

casa-casa-casa

pala-pala-palla

rosa-rossa-rosa

polo-polo-polo

cassa-cassa-casa

bruto-brutto-brutto

notte-notte-notte

penna-pena-penna

pollo-polo-polo

bella-bella-bela

Ejercicio b

casa-bello-vecchio

palla-nero-rosa

bela-petto-colazione

notte-note-collezione

libro-pala-cassa

pollo-pena-anno

brutto-polo-penna

giallo-rosso-bruto

29. Véase MiOnI, op. cit., p. 131-132, nota 27.

30. Véase D'ACHILLE, op. cit. p. 88.

31. Los ejemplos vienen del siguiente libro de italiano para extranjeros: GrUPPO META. Uno. Corso comunicativo di italiano per stranieri. Roma: Bonacci, 1999. p. 202. 
Los estudiantes escucharán la pronunciación de las palabras varias veces y tratarán de entender si cada grupo está compuesto por palabras iguales o diferentes (en el ejercicio $a$ ). Además, tratarán de entender qué palabras tienen consonantes dobles (en los ejercicios $a$ y $b$ ). Después de repetir cada palabra, los alumnos tendrán que escribirlas para memorizarlas.

Para el problema particular de /p/ y /pp/ y /b/ y /bb/:

$\begin{array}{llll}\text { cappello } & \text { lampada } & \text { appartamento } & \text { tipico } \\ \text { abbiamo } & \text { abitare } & \text { mobile } & \text { abbastanza } \\ \text { tappeto } & \text { appuntamento } & \text { ripetere } & \text { troppo } \\ \text { repubblica } & \text { fabbrica } & \text { sabato } & \text { febbraio } \\ \text { arrabiato } & \text { pubblico } & \text { subito } & \text { problema } \\ \text { sopportare } & \text { cappotto } & \text { pepe } & \text { rapporto }\end{array}$

El profesor tendrá que repetir muchas veces las palabras y, si es posible, emplear la grabadora (o bien un vídeo). Luego los estudiantes las pronunciarán y las escribirán. Se podrán hacer ejercicios parecidos con palabras que incluyan otros fonemas del italiano con función distintiva, como $/ \mathrm{t} / \mathrm{y} / \mathrm{tt} / \mathrm{y} / \mathrm{d} / \mathrm{y} / \mathrm{dd} /$.

Para la reduplicación sintáctica es necesario escuchar conversaciones reales de diferentes partes de Italia y hacer observar cómo en las hablas del norte (Emilia, Lombardía, Véneto) el fenómeno no aparece, y en otras (centro-sur) presenta particularidades del estándar florentino (como en Roma, la falta de reduplicación después de $d a$, dove, come con función interrogativa y, en cambio, su presencia después de las interjecciones ah, eh). D'Achille ${ }^{32}$ nota cómo en la tendencia contemporánea hay falta de reduplicación después de monosílabos: tivù por tivvù, senonché por sennonché, y también después de algunos bisílabos: sopratassa, sopratitoli por soprattassa, soprattitoli.

Veamos brevemente unas sugerencias para practicar la reduplicación sintáctica:

a) Escuchar las siguientes frases y luego repetirlas poniendo atención al redoblamiento:

Abita proprio qui dietro

Oggi ho molto da fare

Più tardi vado a casa

Che fa dopo, signorina?

Che cosa ha letto?

Ha visto Lucia?

Tu resta qui, per favore

Va bene cosí

Papà tornerà tardi

Andrea partì di corsa 
b) Reconocer la presencia de dobles consonantes y de reduplicación sintáctica en las siguientes frases:

Ma mi faccia il piacere!

Ha comprato il cappello?

Ciò detto, è uscito sbattendo la porta

$A$ volte avvengono cose assurde

Marina andò via all'improvviso

Che gente c’è a Roma?

$\grave{E}$ impossibile che tutti sappiano e tacciano

Sto bevendo un tè freddo

La mattina a volte prendo un caffé forte

Il fatto glielo dirò domani

\section{Combinaciones de sonidos}

Las sílabas españolas, en cuanto al ordenamiento de los fonemas, límites silábicos, características y división, ${ }^{33}$ tienen rasgos semejantes a las sílabas italianas. Unos ejemplos nos ayudarán a percibir esa similitud:

\section{Italiano}

casa /'ka-sa/

dimora /di-'mo-ra/

quadro /'kwa-dro/

artista /ar-'tis-ta/

costruire /kos-tru-'ire/

aereo /a-'e-reo/

buono /'bwo-no/

\section{Español}

casa /'ka-sa/

demora /de-'mo-ra/

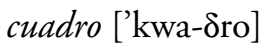

artista /ar-'tis-ta/

construir /kons-tru-ir/

aereo /a-'e-reo/

bueno ['bwe-no]

El estudiante de italiano, sin embargo, debe tener en cuenta lo que hemos dicho con relación a las consonantes dobles, que es el mayor obstáculo para una correcta pronunciación de una combinación de sonidos. Veamos los cambios que la geminación puede producir en la sílaba italiana.

\section{Italiano}

quattro /'kwat-tro/

infiammare /im-fiam-'ma-re/

aggruppare /ag-grup-'pa-re/

acclamare /ak-kla-'ma-re/

\section{Español}

cuatro ['kwa-tro]

inflamar /im-'fla-mar/

agrupar [a-yru-'par]

aclamar [a-kla-'mar] 
Los elementos que constituyen una sílaba son los mismos en ambos idiomas y actúan de la misma manera, con el núcleo (siempre vocálico) en posición central y obligatorio, el ataque en posición prenuclear (puede faltar o bien ser simple o complejo) ${ }^{34}$ y la coda (tampoco obligatoria) en posición posnuclear. El núcleo y la coda (cuando existe) constituyen la rima. Notemos que la coda en español puede tener dos consonantes: /kons-tre-'nir/, mientras que en italiano sólo es posible una consonante /'for-no/, una semivocal /'kau-sa/ y una semivocal + consonante (raro): /'faus-to/. Además, en italiano la sílaba final de palabra es siempre abierta: de hecho, la gran mayoría de las palabras terminan en vocal y, como norma, termina en vocal la palabra al final de la frase, antes de la pausa. ${ }^{35}$ En los dos idiomas prevalece el tipo de sílaba CV (ataque consonántico y rima con un solo núcleo vocálico, sin coda). He aquí el esquema silábico de los dos idiomas:

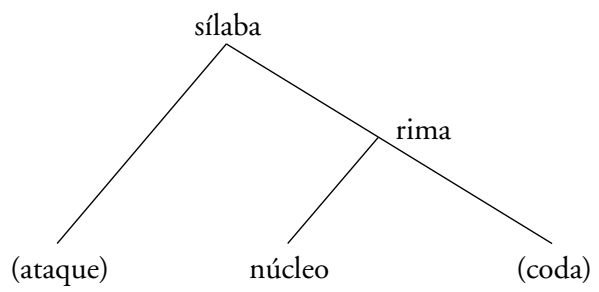

Con el hiato se pueden originar otros problemas con las sílabas (el encuentro de dos vocales en sílabas distintas), ya que a veces se desarrolla de manera un poco distinta en las dos lenguas por la tendencia del italiano a terminar las palabras en vocal:

Italiano

paese / pa-'e-se/

leone / le-'o-ne/

baule / ba-'u-le/

\section{Español}

pais / pa-'is/

león / le-'on/

baúl/ ba'ul/

Además, hay que considerar que el orden de sonidos está compuesto por:

$\begin{array}{ll}\text { I } & \text { el fonema } \\ \text { II } & \text { la sílaba } \\ \text { III } & \text { la palabra } \\ \text { IV } & \text { el sintagma }\end{array}$

El sintagma es la agrupación de dos o más palabras que constituyen una unidad gramatical perfecta y forma la unidad sintáctica intermedia entre la 
palabra y la frase. ${ }^{36}$ Las palabras que forman un sintagma están siempre unidas y no permiten pausas en su interior. El sintagma puede estar compuesto por artículo y sustantivo; adjetivo y sustantivo; tiempos compuestos de los verbos; etcétera.

Hay similitud entre los sintagmas del italiano y los del español. Observemos algunos ejemplos (transcribimos unidas las palabras que originan el sintagma, como en la cadena fónica):

\section{Italiano}

il carro [il'karro]

l'amore [la'more]

il gatto bianco [il 'gatto'bjanko]

ho mangiato molto [oman'dзato 'molto]

Paolo e Marco ['paolem'marko]
Español

el carro [el'karro]

el amor [ela'mor]

el gato blanco [el 'gato'ßlayko]

he comido mucho [eko'mido 'mutso]

Pablo y Marco ['paßli'marko]

También el fenómeno de la sinalefa, que ocurre en el español (como en el último ejemplo de arriba: la pronunciación en una única sílaba de grupos de vocales que enlazan unas palabras con otras en la cadena hablada), ${ }^{37}$ es posible en el italiano y preocupa a los estudiantes.

\section{Italiano}

mio cognato si chiama Enrico [mio ko’nnato si 'kiamen’ríko]

vivo a Malaga

['vivam'malaga]

\section{Español}

mi cuñado se llama Enrique

[mi ku'naoo se ' $\lambda$ amen'rike]

vivo en Málaga

['bißen 'malaya]

Nótese que en el italiano estándar hay reduplicación sintáctica después del monosílabo débil: $a$, y arriba: $e$ (en ['paolem'marko], mientras que el fenómeno no pertenece al castellano estándar. Todas estas particularidades, semejanzas y diferenciaciones entre ambos idiomas en la fonología silábica serán resaltadas por los profesores siempre en el marco de un aprendizaje lo más comunicativo posible.

En esta sección hemos visto los rasgos segmentales del sistema fonológico del español y del italiano. Observemos ahora las características del nivel suprasegmental (o prosódico) del sistema fonológico de ambas lenguas. 


\section{Diferencias entre el italiano y el español: nivel prosódico}

Los fenómenos prosódicos se sobreponen y acompañan a la articulación primaria de sonidos: acento, tono (extremadamente distintivo en idiomas como el chino), ritmo y entonación son los rasgos prosódicos más importantes, pero habría que considerar también la cantidad (como la geminación consonántica del italiano, que aquí hemos incluido en el nivel segmental de análisis para mayor claridad). Recordemos que en el latín clásico y en otras lenguas modernas (como el finlandés y el estoniano), la cantidad vocálica distingue parejas mínimas: finlandés tuli «fuego» y tuuli «viento»; estoniano sada «cien», saada (largo) «enviad», saada (larguísimo) "estar permitido». ${ }^{38}$

También la sílaba podría pertenecer a los fenómenos prosódicos si consideramos que representa un modelo para la utilización de secuencias fonemáticas: en italiano no se permiten secuencias iniciales con $/ \mathrm{kn} /$ (véase alemán knabe "chico») o que acaben en /lms/ (inglés films). Por lo tanto, la sílaba actúa como un filtro que puede excluir secuencias fonemáticas anómalas; además, es el lugar donde se manifiestan algunos importantes rasgos prosódicos, como el acento y el tono, que necesitan de un núcleo vocálico, o sea del centro silábico. ${ }^{39}$

Los fenómenos prosódicos se diferencian de los rasgos segmentales por la falta de discrecionalidad (en el nivel fonemático se individúan los elementos mínimos y discretos que componen y distinguen las diversas unidades); es más complicado analizar los hechos prosódicos que no son discretos en sus manifestaciones físicas. Además, los rasgos prosódicos se emplean para vehicular informaciones paralingüísticas: la entonación, por ejemplo, estructura conversaciones, dando señales de abertura y cierre, e interactúa con la sintaxis y el discurso; ${ }^{40}$ tiene, por tanto, importantísimas funciones pragmáticas.

Veamos ahora si hay diferencias substanciales entre el español y el italiano en prosodia y analicemos en primer lugar el acento.

\section{a) El acento}

El acento es un rasgo prosódico y fonológico, cuya finalidad es poner de relieve una sílaba (o mejor su núcleo) o un grupo de sílabas. Para relevar una sílaba, el acento dispone de tres elementos: intensidad, tono (el chino y el sueco, entre otros, poseen acento de tono, que depende de la frecuencia de la altura musical del sonido) y duración (el francés posee acento de duración, en cuanto la sílaba final del grupo está acentuada porque lleva un suplemento de duración). ${ }^{41}$

38. Véase MAMBERG, op. cit., p. 225-226.

39. Léase Bertinetto, Pier Marco; Magno Caldognetto, Emanuela. «Ritmo e intonazione». En: Sobrero, Alberto A. (coord.). Op. cit., p. 141-192. Aquí la referencia pertinente está en la p. 144.

40. Léase aquí la interesantísima panorámica de BRAZIL, David. Discourse intonation and language teaching. Londres: Longman, 1980.

41. Véase QUILIS y FERNÁNDEZ, op. cit., p. 153. 
La intensidad depende de la amplitud de vibración de las cuerdas vocales. El acento español es de naturaleza intensiva y tiene sólo una sílaba acentuada (salvo los adverbios en mente, que tienen dos). También el italiano posee un acento de intensidad, que se realiza con el aumento de la fuerza espiradora durante la pronunciación del núcleo (vocálico) de la sílaba. Es un acento móvil y no predecible (al igual que en castellano, puede caer sobre cualquier sílaba, aunque ambas lenguas muestran preferencia por la acentuación llana (o paroxítona). Además, la tipología de palabras inacentuadas en las dos lenguas es prácticamente la misma: artículos, preposiciones, algunas conjunciones y pronombres enclíticos conectados a formas verbales. El acento también desempeña cuatro funciones de un modo parecido en los dos idiomas: función contrastiva (puesta de relieve en sílabas y palabras acentuadas frente a las inacentuadas); distintiva (para diferenciar semánticamente dos o más unidades); culminativa (agrupando alrededor de la unidad central otras unidades inacentuadas); y enfática (realzando el interés de una porción de discurso, sea una sílaba, una palabra o una secuencia: /KAFE kiero no 'te/; /'el ESTABA 'aki/; /'kjamo MARKO no 'ssandro/). ${ }^{42}$ Consecuentemente, ambas lenguas poseen un acento de palabra y uno de secuencia (que podríamos definir también como grupo (de secuencias), a diferencia del francés, que lo tiene sólo de grupo. ${ }^{43}$

En las palabras compuestas por más de tres sílabas, el italiano y el español actúan de manera semejante, y llevan el acento secundario [,] sobre la primera o la segunda sílaba: /,kassa'panka/; /,portamo'nete/; /lu,tfida'labbra/, /,korta’plumas/; también agregan pronombres enclíticos (a veces dos o también tres en italiano), lo que causa profundos cambios de acentuación: mèttimicelo, lìberatene, dígaselo, ábremelo. El italiano pone el acento en la sobresdrújula en las terceras personas plurales de algunos verbos en indicativo y subjuntivo: càpitano, isolino, donde la desinencia - no es extramétrica y no se computa como sílaba. El español conoce hasta los octosílabos (como telecomunicaciones), mientras que el italiano tiene la larguísima precipitevolissimevolmente [pre-t $\int \mathrm{i}$-pi-te-vollis-si-me-vol-'men-te], que tiene once sílabas. También hay la protonia sintattica en italiano, por la que, en sintagmas, unas palabras pierden su acento y se apoyan en la siguiente: molto bèllo; era Giùlio; el fenómeno, sin embargo, aparece también en castellano en casos como: muy líndo, era frío.

Algunos inconvenientes podría representar el hecho de que el italiano, salvo pocas palabras oxítonas (città, caffé, perché, etc.), no tiene acento gráfico, a diferencia del español, que tiene un sistema definido de reglas de acentuación: a primera vista, sería posible equivocarse sobre la posición de más intensidad en una secuencia. La experiencia de la enseñanza del italiano como idioma extranjero para hispanohablantes nos demuestra que es complicado saber dónde cae el acento en formas verbales como: amano /ámano/; avevano /avévano/; indicano /índikano/; partecipano/partécipano/. A menudo, los estudiantes sue-

42. Véase Quilis, op. cit., p. 75; AGUILAR, Lourdes, «La prosodia», en Santiago AlCOBA (coord.), op. cit., p. 89-113. Aquí la referencia está en la p. 99.

43. Véase Malmberg, op. cit., p. 52. 
len poner el acento tónico sobre la penúltima sílaba (frecuentísima en castellano) y, por lo tanto, pueden cometer errores de pronunciación.

El italiano y el español se caracterizan por su flexibilidad (a diferencia del francés, que posee una extraordinaria rigidez en cuanto a la posición de la sílaba acentuada, siempre la última), que crea cambios semánticos importantes según donde caiga el acento. Observemos algunos ejemplos:

Italiano

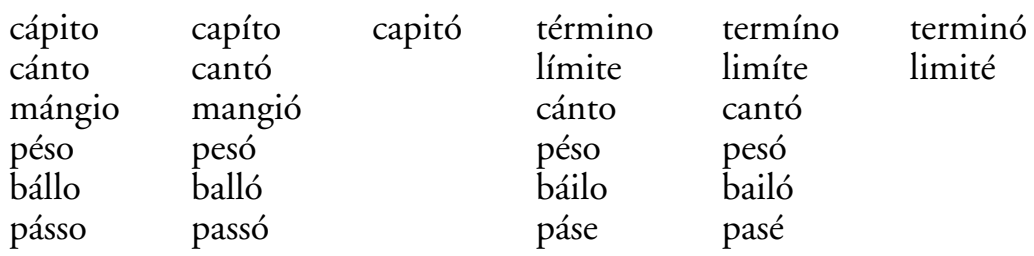

En el italiano contemporáneo, hay tendencia a retraer el acento, así que palabras paroxítonas u oxítonas se realizan como proparoxítonas: èdile por edìle; sàlubre por salùbre; Pàkistan per Pakistàn. También se cambia el acento en apellidos típicos del norte (Véneto): Bènetton por Benettòn; Trèvisan por Trevisàn. ${ }^{44}$

Así pues, en cuanto al acento, se puede decir que hay modelos parecidos entre los dos idiomas, a pesar de la casi falta de acento ortográfico en el italiano, que en general confunde mucho a los estudiantes extranjeros: sin embargo, las esdrújulas casi siempre tienen la penúltima sílaba abierta: tàvolo, pàpera, bròccoli, cèlibe, pero a veces no: màndorla. Se podría usar esta particularidad silábica para reducir los potenciales errores de pronunciación. Mioni ${ }^{45}$ propone mirar si la penúltima sílaba tiene coda: si es así, la sílaba será acentuada en la gran mayoría de los casos, como en contènto, rispòsta, cartùccia, compàrsa. Se exceptúan sólo pocos topónimos de sur de Italia (sobre todo de Apulia): Òtranto, Tàranto, Òfanto. Con la excepción de unas formas verbales con doble y sobre todo triple pronombre enclítico agregado, la mayoría de las palabras italianas presentan, por tanto, secuencias gráficas conocidas por hispanófonos que, practicando muy especialmente las esdrújulas y teniendo en mente unas simples sugerencias como las indicadas arriba, llegarán a un buen control global del acento italiano.

\section{b) El ritmo}

Cada idioma tiene un ritmo característico que particulariza la procedencia de un extranjero que habla una segunda lengua. El ritmo es una sensación perceptiva provocada por la sucesión en el habla de segmentos marcados y no 
marcados. Puede estar condicionado por el acento, la intensidad y la velocidad (tiempo de elocución). ${ }^{46}$ Dado que la velocidad y la intensidad de un discurso dependen también de factores poco analizables en este contexto (el ámbito social en que se realiza la emisión; la presencia o no de pausas y su completo dominio; las características del medio de transmisión: en un salón ruidoso y todavía más en un estadio la intensidad aumentará, mientras que delante de un micrófono bajará), podemos dedicarnos al problema del acento rítmico. La percepción del ritmo en el grupo fónico (la porción de discurso comprendida entre dos pausas significativas) depende de cuánto se puedan comprimir las sílabas átonas de esa misma cadena: el inglés también comprime mucho las sílabas átonas en el habla, strengths, porque posee secuencias fonológicas desconocidas para el español y el italiano. ${ }^{47}$ Diremos, por tanto, que su ritmo depende del número de sílabas acentuadas y no del número total de sílabas de la frase: I explained it to Billy se produce en un lapso de tiempo muy cercano a: I told Billy. Es decir, que en inglés una oración extensa (digamos unas treinta sílabas) se termina más rápidamente que en italiano, también por la distinta manera de dividir la sílaba. En cambio, el italiano y el español se resisten mucho a la reducción silábica en elocución rápida, y conservan todas las sílabas de la oración con una rigidez substancial: ${ }^{48}$ su ritmo depende del número global de sílabas que hay en una cadena fónica. La sílaba, pues, marca el compás y el tiempo empleado por un nativo español o italiano en un enunciado dependerá en gran parte del número de sílabas: un enunciado de treinta sílabas durará más o menos el doble que uno de quince. ${ }^{49}$ Sin embargo, el debate crítico sobre este tópico está muy abierto: considerando que nuestras dos lenguas son isosilábicas (consienten sólo un grado muy limitado de compresión de sílabas átonas), podríamos predecir una buena comprensión y un buen manejo de los factores rítmicos del italiano, cuya adquisición es seguramente menos complicada que la de las lenguas con un ritmo acentual como el inglés. Naturalmente, debemos tener en cuenta que el ritmo, como la entonación, aún más que los factores segmentales, depende de las variantes geográficas, sociolingüísticas y personales (idiolecto). Sin embargo, considerando el sistema estándar de los dos idiomas, no se notan diferencias esenciales en el ritmo de la conversación. Con referencia al italiano contemporáneo, se ha notado que en el sureste de Italia (Apulia y Lucania) se realiza un ritmo de tipo acentual, en el centro y en el Véneto se da un ritmo silábico, y en Calabria hay zonas intermedias con ritmo en parte silábico y en parte acentual. ${ }^{50}$

46. Véase AgUILAR, Lourdes, "La prosodia», op. cit., p. 109-110.

47. Véase Bertinetto y Magno Caldognetto, op. cit., p. 147-154.

48. Véase ibidem, p. 149.

49. Véase QUILIS y FERNÁNDEZ, op. cit., p. 160.

50. Véase Bertinetto y Magno Caldognetto, op. cit., p. 152. 


\section{c) La entonación}

La entonación es la principal característica de la frase y depende de las variaciones de la frecuencia de vibración de las cuerdas vocales. Abarca la totalidad de la frase y puede contribuir tanto al cambio de su significado como a la expresión de determinados estados psíquicos o de determinados sentimientos (ira, desprecio, etc.). ${ }^{51}$ Además, la entonación estructura las conversaciones: ${ }^{52}$ da señales para aberturas, cambios de turno y cierre de las mismas. Simone $e^{53}$ añade el concepto de la interfaz fonológico-estructural: la entonación no contiene sólo informaciones fonológicas, sino que nos informa sobre la naturaleza y organización estructural del enunciado, ya que el receptor puede asignar una estructura a las oraciones que recibe. La correcta entonación de un enunciado es más importante que la producción de cada sonido en particular. Una mala entonación desvirtúa completamente la pronunciación correcta de fonemas y alófonos y connota negativamente al hablante, sea autóctono o extranjero. ${ }^{54} \mathrm{La}$ entonación, pues, tiene una función fonológica y asigna significados específicos a palabras individuales o secuencias de ellas en oraciones, como cuando distingue una frase declarativa de una interrogativa o exclamativa; y, sobre todo, tiene una función pragmática, ya que nos regala informaciones suplementarias de tipo connotativo, afectivo, estético, expresivo y también sociolingüístico, por medio de las cuales los sentimientos y las emociones (maravilla, rabia, mando, felicidad, reproche) marcan en sentido subjetivo la oración. ${ }^{55}$ Simone ${ }^{56}$ habla también de la importancia biológica de ese factor prosódico: el recién nacido produce sencillas curvas melódicas ya en los primeros días de vida, mucho antes de poder articular un fonema cualquiera en cada lengua; el niño comienza en seguida a imitar las entonaciones de su madre, y hacia los tres meses llega a producirlas, incluso con la misma duración. Cuando tiene un año de vida, el niño prácticamente ya ha aprendido la gama esencial de las entonaciones propias de su lengua materna.

Más detalladamente, al describir la entonación hay que considerar la unidad melódica (la porción más corta del habla con sentido propio y forma entonativa específica), cuyos límites coinciden con pausas o variaciones del tono, incluso en una misma oración, según el hablante o el ritmo (velocidad) de elocución; ${ }^{57}$ el grupo fónico, que es la parte del habla incluida entre dos pausas sucesivas (en español el grupo fónico oscila entre ocho y once sílabas): 58 // Juan es alto / simpático / elegante// (tres grupos fónicos separados

51. Véase QuiLIs, op. cit., p. 164.

52. Véase BRAZIL, op. cit.

53. Véase SimOne, Raffaele. Fondamenti di linguistica. Roma-Bari: Laterza, 1990. p. 334 y ss.

54. Véase OdLIN, op. cit., p. 56-57.

55. Léase la panorámica sobre los diferentes tipos de entonaciones en MORETTI, Giovanni Battista. Litaliano come prima o seconda lingua. Perugia: Guerra, 1996. p. 31.

56. Véase op. cit., p. 102.

57. Véase Aguilar, «La entonación». En: Alcoba, Santiago (coord.). Op. cit. p. 116.

58. Véase QUilis y FERNÁNDEZ, op. cit., p. 163. 
por pausas); y el grupo de entonación, que es la parte del habla comprendida entre dos pausas, entre pausa e inflexión tonal, entre inflexión tonal y pausa, o entre dos inflexiones tonales. La inflexión tonal es la variación de la línea tonal del enunciado en muy poco tiempo con movimiento descendente o ascendente. ${ }^{59} \mathrm{El}$ grupo de entonación se diferencia del grupo fónico si no hay pausas en la emisión de una oración como la de arriba: // Juan es alto $\downarrow$ simpático $\downarrow$ elegante $\downarrow / /$ (donde $\downarrow$ señala descenso tonal, mientras que $\uparrow$ señalaría ascenso).

Analizando la unidad melódica, podemos dividirla en tres partes: rama inicial, que incluye todas las sílabas hasta el primer acento; cuerpo (o núcleo), desde la primera sílaba acentuada hasta la sílaba anterior al último acento; y rama final, o sea la última tónica más el resto. ${ }^{60}$ Pensemos en una frase del castellano como: El profesor preparó las tareas; y en la correspondiente en italiano: Il professore preparò i compiti. Segmentando las frases tendremos:

$\begin{array}{lll} & \text { Español } & \text { Italiano } \\ \text { Rama inicial } & \text { Iel-profe-l } & \text { Iil-profes-/ } \\ \text { Núcleo } & \text { Isor-preparó-las-ta-/ } & \text { Isor-preparó-icom-/ } \\ \text { Rama final } & \text { Ireas/ } & \text { Ipitil }\end{array}$

Parece, pues, que la unidad melódica se expresa de manera semejante en los dos idiomas, por lo menos a un nivel de análisis muy esencial: se podría presuponer, pues, una similitud también en la curvas melódicas del enunciado. Esas curvas tienen unas formas típicas según el tipo de oración y esta forma se llama patrón melódico. ${ }^{61}$ Podemos observar con Aguilar ${ }^{62}$ que el patrón melódico es lo que diferencia el sentido de frases que de otro modo serían iguales. Veamos estas oraciones en español e italiano:

Pedro habla con Pablo

¿Pedro habla con Pablo?

¿Pedro habla con Pablo!
Pietro parla con Paolo

Pietro parla con Paolo?

Pietro parla con Paolo!

La primera, asociada con un patrón melódico enunciativo, expresa una información; la segunda, con un patrón interrogativo, formula una pregunta; y la tercera, con un patrón exclamativo, transmite una emoción (que puede ser de diferente tipo).

Ambas lenguas, por tanto, comparten la posibilidad de cambiar el sentido a la oración por medio de un patrón melódico: vemos ahora en detalle si hay diferencias en estos patrones melódicos, o sea en las formas de las líneas entonativas asociadas a un determinado tipo de frase.

59. Véase AgUilar, "La prosodia», op. cit., p. 110.

60. Véase ibidem.

61. Véase Aguilar, «La entonación», op. cit., p. 117.

62. Véase ibidem, p. 120. 
Seguimos aquí la línea de investigación propuesta para el castellano, sobre todo por Quilis y Fernández ${ }^{63}$ y, en parte, por Aguilar; ${ }^{64}$ la confrontaremos con el trabajo de Canepari ${ }^{65}$ y con otros, aunque somos responsables, con referencia al italiano, de cómo tratamos aquí este rasgo prosódico, y nos interesa más ver las similitudes y las diferencias que hay entre las dos lenguas en entonación, que entrar en los profundos y específicos tratados teóricos y científicos de la materia. ${ }^{66}$

Empezaremos la discusión distinguiendo entre las variaciones tonales que existen en el interior de las frases y que dependen de variantes geográficas, sociolingüísticas o individuales; y las variaciones tonales que aparecen al final del grupo de entonación. Estas últimas variaciones (tonemas) son los elementos lingüísticamente más significativos de la propia entonación.

En ambos idiomas el tonema puede presentar tres movimientos fonológicos: ascendente, horizontal y descendente, con bastantes similitudes.

El tonema descendente puede terminar (en la realidad fonética) en cadencia (oraciones afirmativas e interrogativas parciales o retóricas) o en semicadencia (expresiones que dan una idea insuficientemente definida o que se utilizan para contradecir y/o corregir declaraciones anteriores). Veamos los siguientes ejemplos:

\section{CADENCIA}
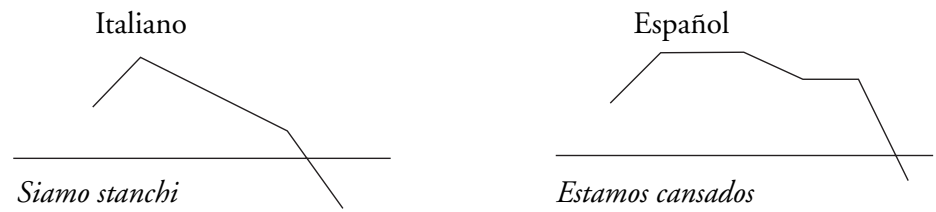

SEMICADENCIA

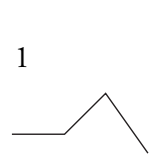

Italiano

2

3
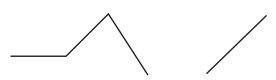

il vivente / il presente / l'attuale

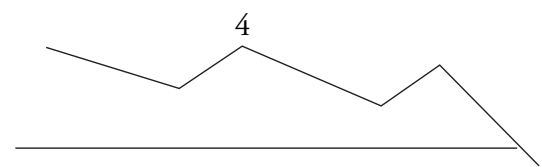

é ció che chiamiamo moderno

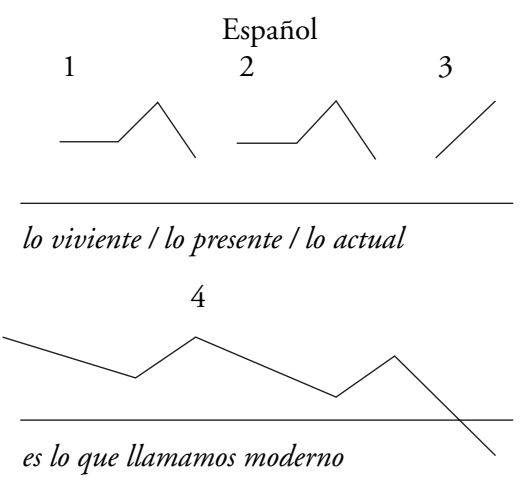

1 y 2: tonema en semicadencia; 3: tonema en anticadencia; 4: tonema en cadencia.

63. Véase op. cit., p. 163 y ss.

64. Véase AGUilaR, «La entonación», op. cit., p. 115 y ss.

65. Véase op. cit., p. 165 y ss.

66. Véase, por ejemplo, BertinetTo y Magno CaldognetTo, op. cit., p. 155 y ss. 
El tonema horizontal (suspensión) se utiliza en frases con sentido incompleto o en las frases que necesitan una continuación. Además, se encuentra en frases con contenidos indecisos y en las enumeraciones. Aquí el tonema finaliza al mismo nivel que el cuerpo del grupo fónico en el que está situado.

\section{SUSPENSIÓN}

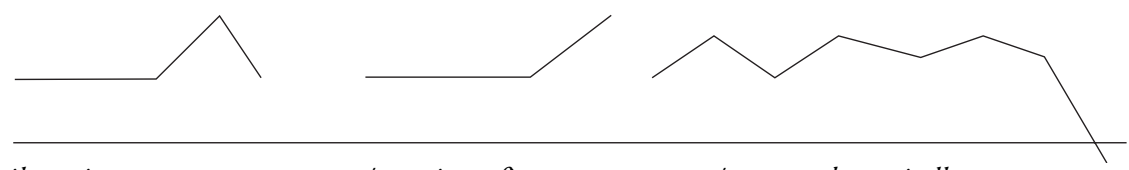

il nemico Iquasi sconfitto

I correva davanti alle nostre truppe

tonema en suspensión / tonema en anticadencia / tonema en cadencia

Estos rasgos tonales serán los mismos para la frase española correspondiente: El enemigo, casi derrotado, corría delante de nuestras tropas.

El tonema ascendente puede acabar en anticadencia, como en las frases interrogativas absolutas o en los proverbios; o en semianticadencia (que termina a una altura menor que la anticadencia), en el caso de expresiones de duda, de sorpresa y en las preguntas-eco (como: Ho visto Marco. Hai visto chi?; Andiamo in strada. A far che?). Veamos los ejemplos.

\section{ANTICADENCIA}

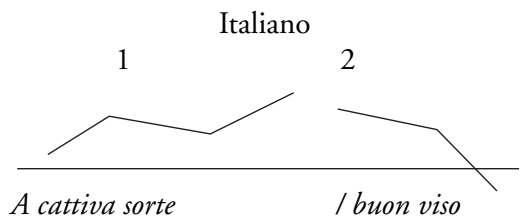

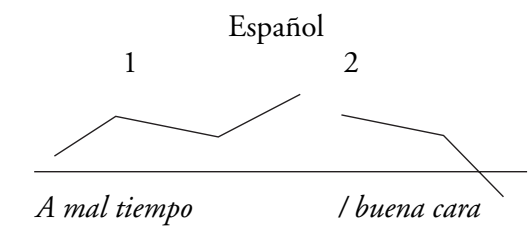

Español

1: tonema en anticadencia; 2: tonema en cadencia.

\section{SEMICADENCIA}

Italiano

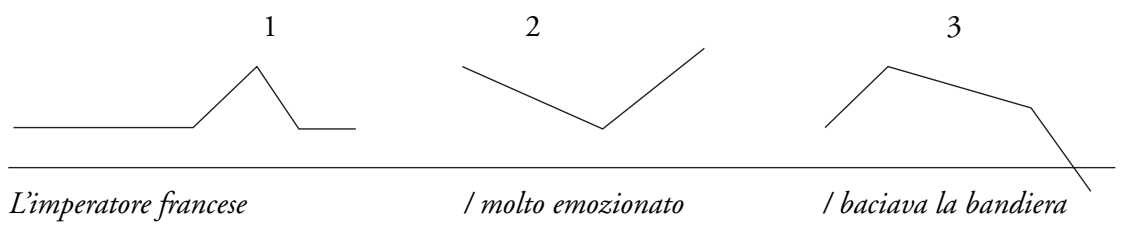

1: tonema en suspensión; 2: tonema en semianticadencia; 3: tonema en cadencia.

Las mismas realizaciones tonales se darán en la frase española de igual contenido: El emperador francés, muy emocionado, besaba la bandera. 


\section{La entonación en la frase enunciativa}

Hemos visto que la entonación varía según el número de grupos fónicos que contenga la frase. El mismo fenómeno ocurre en italiano y en español. Una oración enunciativa con un solo grupo fónico terminará en cadencia; con dos grupos fónicos, el primero termina en anticadencia y el segundo en cadencia, como hemos visto en los ejemplos más arriba. Cuando en la frase hay más de un grupo fónico, es conveniente diferenciar entre una rama tensiva (la parte del discurso situada entre el inicio de la frase y el primer punto tonal máximo) y una rama distensiva (comprendida entre el primer punto tonal máximo y el final de la frase). ${ }^{67}$ Aguilar ${ }^{68}$ nota que también podría ocurrir, en las enunciativas, el esquema tonal semicadencia-cadencia, cuando la frase es yuxtapuesta o tiene coordinadas adversativas. Normalmente, en todos los tipos de frases enunciativas el último grupo fónico termina en cadencia. También Canepari ${ }^{69}$ confirma este punto para las oraciones declarativas neutras. Bertinetto y Magno Caldognetto $^{70}$ reiteran que en italiano hay un movimiento final descendente en las frases enunciativas con estructura SVO, algo común en muchas lenguas, casi a nivel de universal lingüístico.

\section{La entonación en la frase interrogativa}

Normalmente la frase interrogativa en el italiano y en el español termina en tonema ascendente y en anticadencia, como mostramos en los ejemplos; es decir, los dos idiomas poseen una entonación ascendente en las frases interrogativas absolutas (las que requieren una respuesta del tipo sí-no.)

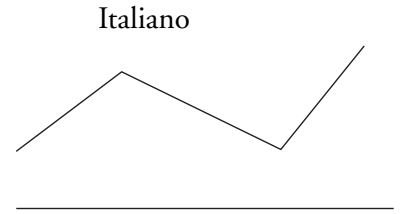

Parla spagnolo?
Español

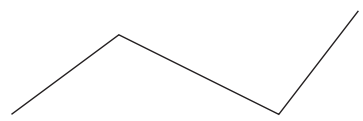

¿Habla español?

Los dos idiomas diferencian la frase interrogativa de la declarativa sólo con el uso del movimiento entonativo ascendente, lo que demuestra que la entonación es una parte esencial, y no opcional, de sus sistemas lingüísticos. En realidad, en italiano, la voz sube y baja más de una vez sobre los principales elementos de la entonación en frases interrogativas extensas, pero siempre termina en tonema ascendente, así que la cadena melódica no es muy diferente de 
la del español (también la discusión expuesta por Aguilar ${ }^{71}$ nos conforta en ese sentido).

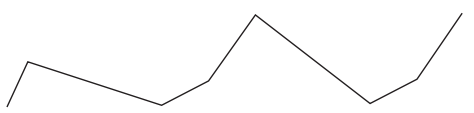

Volete accompagnarmi a Milano domani?

(¿Quieren ustedes venir conmigo a Milán mañana?)

Otra similitud entre los dos idiomas se encuentra cuando la frase interrogativa comienza por un pronombre o un adverbio interrogativo, palabras que llevan acento tónico y gráfico en español y sólo tónico en italiano (las interrogativas parciales). En español, el tonema desciende y termina en cadencia y lo mismo ocurre en italiano (con adverbio + verbo simple), porque el elemento tónico inicial es por sí solo indicador de la interrogación. En italiano también es posible el tonema ascendente que termina en anticadencia si hay otros elementos en la frase interrogativa.

Ejemplos:

Italiano

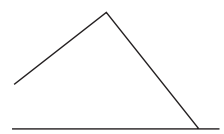

Dove stai?
Italiano

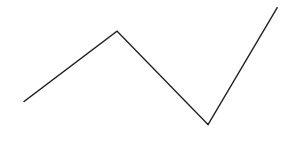

Dove sta Angelo?
Español

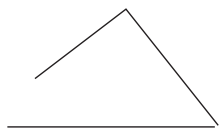

¿Dónde estás?

Cuando, con los mismos operadores interrogativos, queremos hacer preguntas de cortesía, utilizaremos, en ambos idiomas, dos rasgos juntos: la palabra interrogativa y la entonación ascendente. ${ }^{72}$ Una pregunta como: ¿cuánto cuesta?, producida según el modelo de arriba, podría, en algunos contextos, resultar poco cortés, y por eso emplearemos un patrón melódico ascendente.

Naturalmente, debemos tener en cuenta que muchas frases interrogativas cambian su melodía según el resultado que la persona que interroga espera obtener del interrogado. Por ejemplo, en las preguntas Hai la chiave? y ¿Tienes la llave?, si el que hace la pregunta duda de que el interrogado tenga la llave, el tonema será ascendente; por el contrario, si sabe que la tiene, el tonema terminará en cadencia.

Otro rasgo en común en la entonación del italiano y del español se da en el caso de la interrogación ratificada (domanda coda en italiano). Se formarán 
dos grupos fónicos: el primero termina en cadencia o semicadencia (tonema descendente; el segundo, en anticadencia (tonema ascendente).

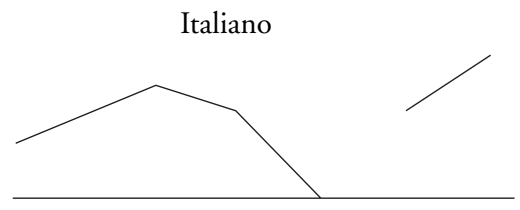

Non sei stanco

/ vero?

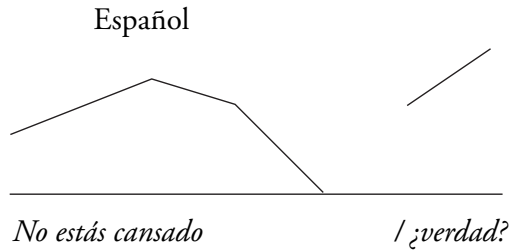

Además, las frases imperativas y exclamativas tienen rasgos semejantes en los dos idiomas. La frase imperativa, de hecho, termina en tonema descendente, en cadencia. Esto ocurre cuando a ese tipo de frase (normalmente formada por un sólo grupo fónico: Dame un cuaderno) se añaden frases de cortesía, como por favor, haga el favor, etc. En este caso, el penúltimo grupo termina en semicadencia y el último, en cadencia, como en el caso del italiano: Dammi un quaderno, per favore, y en el español: Dame un cuaderno, por favor. Por otra parte, las frases exclamativas se caracterizan porque varían el tono medio de la frase, que es más alto que en las enunciativas, y por su fuerte variabilidad tonal en segmentos cortos. ${ }^{73}$ Quilis ${ }^{74}$ y Quilis y Fernández ${ }^{75}$ afirman que la oración exclamativa acaba con un tonema descendente, pero Aguilar $^{76}$ nos dice que es problemático encontrar en este tipo de frase un patrón melódico sistemático (por los distintos matices emotivos que cargan): se puede, por lo tanto, buscar líneas tonales ascendente-descendente (en emociones extremas, como entusiasmo y desesperación), sólo ascendente (para denotar sorpresa y extrañeza) y sólo descendente (para expresar reproche o resignación), con tonos muy altos y móviles para la exaltación y tonos bajos, muy monótonos, en estados de ánimo deprimidos. ${ }^{77}$ En italiano, Canepari ${ }^{78}$ parece indicar, con unos ejemplos de frases enfáticas, que el tonema final es sobre todo descendente; creemos que en frases como: iquién lo hubiera dicho! y su equivalente italiano chi l'avrebbe detto!, que expresan una fuerte sorpresa, el tonema final es, sin embargo, ascendente, lo que denota también una semejanza positiva entre ambos idiomas.

Con referencia al aspecto sociolingüístico de la entonación, Quilis ${ }^{79}$ nos informa de que las interrogativas absolutas del castellano de Puerto Rico suelen acabar en tonema descendente y en fuerte cadencia, en clara oposición al esquema melódico del español estándar. Canepari ${ }^{80}$ nos muestra las entona-

73. Véase ibidem, p. 133.

74. Véase $o p$. cit., p. 85.

75. Véase op. cit., p. 181.

76. Véase «La entonación», op. cit., p. 133.

77. Véase ibidem, p. 138.

78. Véase $o p$. cit., p. 167.

79. Véase op. cit., p. 82-83.

80. Véase $o p$. cit., p. 171 y ss. 
ciones conclusivas (de las frases enunciativas), interrogativas y suspensivas (que avisan al oyente de que algo importante seguirá en la conversación) del italiano estándar y de todas sus variantes regionales (veintiuna en el estudio): el interesantísimo trabajo nos indica que hay diferenciaciones claras según la región de procedencia del hablante (por ejemplo, las interrogativas absolutas con tonema descendente en Lombardía, Apulia, Alto Adigio, Friuli y Cerdeña), y que, si se encuentran notables variaciones prosódicas en la lengua italiana, hablada fundamentalmente en un solo país (también en Suiza, Córcega, Istria y Dalmacia), es aún más lógico esperarlas en el idioma español, que tiene una difusión amplísima e intercontinental.

Además, para determinar el movimiento entonativo de una frase, es importante su estructura sintáctica y sobre todo su estructura informativa: las dos no siempre coinciden ${ }^{81}$ y es posible que en una frase como: Paolo mangia la mela, el tema conocido sea Paolo y la información nueva sea mangia la mela, como ocurre normalmente (y tendremos una entonación descendente). Pero la información nueva podría ser cambiada por todas las preguntas contextuales posibles: ¿quién come la manzana?; ¿qué hace Pablo?; ¿qué come Pablo?. El movimiento entonativo de frases declarativas e interrogativas puede, pues, cambiar según qué sintagma se quiere focalizar en una oración: sin embargo, se nota que, aun con curvas melódicas diferentes en su interior, las frases terminan según los modelos de entonación arriba expuestos. Ambos idiomas poseen esta posibilidad de modificar la focalización de elementos en el interior de oraciones y suponemos que actúan de manera muy parecida.

Resumiendo, el italiano posee tres tonemas fundamentales: el conclusivo, con bajada de la nota de la vocal tónica de la última palabra; el interrogativo, con subida de la nota sobre la última sílaba de la última palabra; y el suspensivo, se mantienen las mismas notas de las sílabas anteriores o bien sube la nota sobre la vocal tónica y después baja de nuevo. Veamos los tres tonemas fundamentales: ${ }^{82}$

Carlo è partito stamattina

$\overbrace{\text { Carlo è partito stamattina? }}^{\nearrow}$

$\longrightarrow \lambda$

Me l'avevano detto che non volevi venire

Me l'avevano detto che non volevi venire

81. Véase Bertinetto y Magno Caldognetto, op. cit., p. 171.

82. Véase MORETTI, op. cit., p. 31. 
Como podemos ver, los tres tonemas coinciden con las propuestas de Quilis y Fernández para el castellano). ${ }^{83}$ Por lo tanto, lo que hemos dicho sobre la entonación en el italiano y en el español parece mostrar semejanzas entre los rasgos melódicos de los dos idiomas. Sin embargo, si analizamos de una manera más científica, con representaciones oscilográficas y control (en hertz) de la frecuencia fundamental en contextos comunicativos, descubriremos ciertas diferencias inevitables entre las dos lenguas; además, aquí no hemos tratado con amplitud el fenómeno del habla rápida (el allegro), que tiene muchas implicaciones en los aspectos fonológicos (segmentales y prosódicos) del italiano (piénsese en los fenómenos de coarticulación, ${ }^{84} \mathrm{o}$ sea asimilación, aféresis vocálicas y silábicas, tendencia contemporánea de los hiatos a transformarse en diptongos). ${ }^{85}$ Aconsejamos presentar fragmentos de italiano allegro en las clases que ya tienen un buen nivel de conocimientos fonológicos esenciales; nos hemos percatado de que existen diferencias que se deben a las variedades geográficas, sociolingüísticas y personales; pero, en una organización estándar de los dos idiomas, los fenómenos melódicos se pueden considerar bastante similares y se puede presuponer una transferencia lingüística positiva; ${ }^{86}$ además, con una buena práctica de ejercicios, como escuchar y repetir frases específicas en contextos comunicativos (poniendo atención a las variaciones lingüísticas regionales de Italia que hemos visto antes), estos fenómenos pueden ser dominados por los estudiantes de italiano.

Presentamos ahora ejercicios para escuchar y repetir para acercarse en lo posible a la entonación del italiano estándar. Empezaremos con frases enunciativas:

Ho visto Paolo due minuti fa. Lucia non ha ancora telefonato.

Volevo delle informazioni sui corsi Non sono ancora stata a Parigi. d'Italiano.

Domani ho un sacco da fare. Devo lavorare tutto il giorno.

In questa stagione non piove mai. $\quad$ Non ho piú soldi, non so come fare.

Veamos ahora unas frases interrogativas:

Scusa, come hai detto che ti chiami? Vi va di accompagnarmi a Firenze domani? Ti posso aiutare? Perché sono arrivati tardi?

Quale preferisce tra queste giacche? Come si sente tua sorella oggi? Mi date il vostro indirizzo? Che ne pensate del nuovo libro di Umberto Eco? 


\section{Conclusiones}

Hemos visto que el español y el italiano tienen bastantes semejanzas en el sistema fonológico, especialmente en el sistema vocálico, en la sílaba (aun teniendo en cuenta la geminación en el italiano) y, en buena parte, en el nivel prosódico (acento, ritmo, entonación). Por estos factores, es posible presuponer una transferencia positiva alta de una lengua a la otra, ${ }^{87}$ y condiciones favorables para un buen dominio del italiano.

Este trabajo puede indicar que las mayores dificultades para los hispanohablantes en el aprendizaje del sistema fonológico del italiano serán algunos fonemas y secuencias de fonemas consonánticos (especialmente los africados), que el español no posee; algunos problemas de transferencia de hábitos lingüísticos del idioma materno (transferencia lingüística negativa ${ }^{88}$ en la pronunciación de algunas palabras en italiano (['gerra] por /'gwerra/; ['t $\left.\int i m i k a\right]$ por /'kimika/); variaciones naturalmente posibles en el nivel prosódico y, en particular, una diferencia de entonación en algunas frases interrogativas extensas (donde la entonación en el italiano baja y sube muchas veces, un poco más que en el español); y, sobre todo, el fenómeno de la geminación (o duplicación de consonantes), que está muy difundido en italiano y es casi desconocido en español (exceptuando /rr/ y [nn]). Este fenómeno puede causar dificultades en la división silábica y posibles alteraciones en el ritmo de la cadena hablada. Por lo tanto, los profesores deben tratarlo con atención e insistir sobre la correcta pronunciación de las palabras con las consonantes dobles en contextos comunicativos.

Hemos presentado unas sugerencias para ayudar a los estudiantes a mejorar su producción de consonantes dobles, sonidos particulares y también la entonación italiana. Sólo con el trabajo continuo y motivado, con interés y con la ayuda de sus profesores, los estudiantes hispanófonos podrán disfrutar de la excelente posibilidad de aprender con éxito el sistema fonológico del italiano, un idioma naturalmente familiar por parecerse al español.

A continuación presentamos las tablas de fonemas y principales alófonos consonánticos del español y del italiano (a la izquierda, las sordas; a la derecha, las sonoras; y entre corchetes, los alófonos) y después los triángulos vocálicos de los dos idiomas. 
Tabla 1. Fonemas consonánticos del español según el modo y punto de articulación.

\begin{tabular}{|c|c|c|c|c|c|c|}
\hline Modo & Bilabial & Labiodental & Dental & Alveolar & Palatal & Velar \\
\hline Oclusivas & $\begin{array}{l}\mathrm{p} \\
\mathrm{b}\end{array}$ & & $\mathrm{t} \quad \mathrm{d}$ & & & k $\quad \mathrm{g}$ \\
\hline Fricativas & {$[\beta]$} & $\mathrm{f}$ & $\Theta[\delta]$ & s & j & $\mathrm{x} \quad[\gamma]$ \\
\hline Africadas & & & & & $\operatorname{tg}\left[\mathrm{d}_{3}\right]$ & \\
\hline Nasales & $\mathrm{m}$ & {$[\mathrm{m}]$} & {$[\mathrm{n}]$} & $\mathrm{n}$ & $\mathrm{n}$ & {$[\mathrm{y}]$} \\
\hline Laterales & & & [1] & 1 & $\lambda$ & \\
\hline Vibrantes & & & & $\begin{array}{l}\mathrm{r} \\
\mathrm{rr}\end{array}$ & & \\
\hline
\end{tabular}

Tabla 2. Fonemas consonánticos del italiano según el modo y punto de articulación.

\begin{tabular}{|c|c|c|c|c|c|c|}
\hline Modo & Bilabial & Labiodental & Dental & Alveolar & Palatal & Velar \\
\hline Oclusivas & $\begin{array}{l}\mathrm{p} \\
\mathrm{b}\end{array}$ & & $\mathrm{t} \quad \mathrm{d}$ & & & $\mathrm{k} \quad \mathrm{g}$ \\
\hline Fricativas & & $\mathrm{v}$ & & $\mathrm{z}$ & $\int[3]$ & \\
\hline Africadas & & & & $\begin{array}{l}\text { ts } \\
\mathrm{dz}\end{array}$ & $\operatorname{tg}[\mathrm{b}]$ & \\
\hline Nasales & $\mathrm{m}$ & {$[\mathrm{m}]$} & {$[\mathrm{n}]$} & $\mathrm{n}$ & $\mathrm{n}$ & {$[\mathrm{y}]$} \\
\hline Laterales & & & {$\left[\begin{array}{l}1 \\
1\end{array}\right]$} & 1 & $\lambda$ & \\
\hline Vibrantes & & & & $\mathrm{r}$ & & \\
\hline
\end{tabular}

Tabla 3. Triángulos de las vocales españolas e italianas.

Español

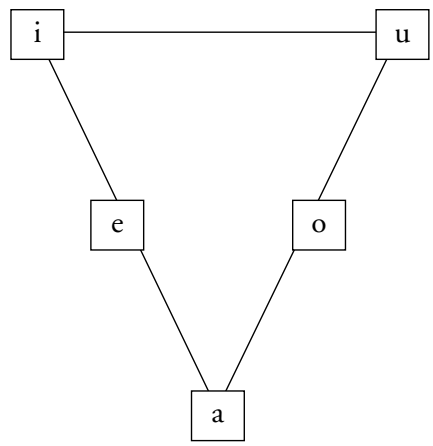

Con semiconsonantes y semivocales [w] [j]
Italiano

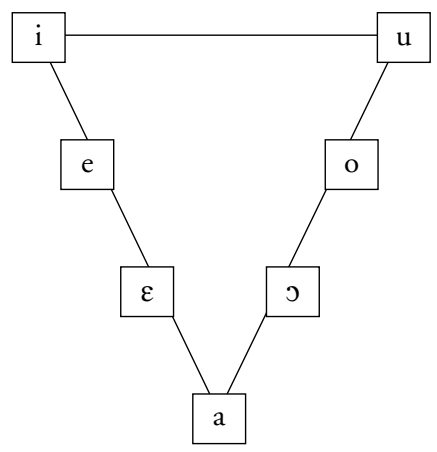

Con semiconsonantes y semivocales $/ \mathrm{w} / / \mathrm{j} /$ 